\section{RET, set, go}

\section{By Chris Cain, Senior Writer}

Just 15 months after Ret proto-oncogene fusions were first identified in $1 \%-2 \%$ of non-small cell lung cancer cases, early data from a Phase II trial of Exelixis Inc.'s Cometriq cabozantinib suggest that blocking the target could be effective in this patient population. ${ }^{1}$ At least four additional investigator-initiated trials are seeking to test marketed Ret proto-oncogene inhibitors in fusion-positive lung cancer.

In addition, at least seven clinical trials are testing compounds that inhibit other recently identified oncogenic drivers of lung cancer, including amplifications or mutations in fibroblast growth factor receptors (FGFRs) and mutations in discoidin domain receptor tyrosine kinase 2 (DDR2) (see Table 1, "Selected new targeted therapies in lung cancer" and Box 1, "Squamous smorgasbord").

The rapid move to the clinic validates the prediction made by clinicians and industry researchers that the identification of new oncogenic drivers of lung cancer would spur the development of targeted therapies for new subsets of patients. ${ }^{2-5}$

In late 2011 and early 2012, four independent teams reported the expression of a KIF5B-RET oncogenic fusion protein in non-small cell lung cancer (NSCLC) patient samples and showed that the protein was necessary and sufficient to drive unchecked cellular proliferation. ${ }^{6-9}$ This drew immediate comparisons to the 2007 identification of the EML4ALK oncogenic fusion protein, which drives about $5 \%$ of NSCLC cases. ${ }^{10}$

A key difference is that when EML4-ALK was discovered, there were no marketed anaplastic lymphoma kinase (ALK) inhibitors. Pfizer Inc.'s Xalkori crizotinib, a dual inhibitor of c-Met receptor tyrosine kinase and ALK and their oncogenic variants, entered the clinic in 2006 and was approved in August 2011 to treat ALK fusion-positive lung cancer. ${ }^{4}$

In contrast, Ret proto-oncogene (RET) kinase is inhibited by multiple marketed nonspecific tyrosine kinase inhibitors, including Cometriq, Nexavar sorafenib, Sutent sunitinib, Caprelsa vandetanib and Iclusig ponatinib.

Cometriq is marketed by Exelixis to treat medullary thyroid cancer (MTC). Nexavar is marketed by Onyx Pharmaceuticals Inc. and Bayer AG to treat liver and renal cancers. Sutent is marketed by Pfizer to treat gastrointestinal stromal tumors (GISTs) and advanced renal cell carcinoma (RCC). Caprelsa is marketed by AstraZeneca plc to treat MTC. Iclusig is marketed by Ariad Pharmaceuticals Inc. to treat certain refractory leukemias.

Naiyer Rizvi, a medical oncologist at Memorial Sloan-Kettering Cancer Center, told SciBX that the availability of these inhibitors made it possible to immediately test whether inhibiting RET would have clinical benefit in patients with RET fusion-positive lung cancer.

"The stars aligned to allow us to move this forward so quickly. When

the RET fusion was first reported in December 2011, we saw that it fit the profile of other oncogenes that have been described in lung cancer in that it is a tyrosine kinase fusion in patients who have never smoked. We were in a lucky position where there was a drug available that targets VEGF and c-Met but also targets RET, so we contacted Exelixis and they provided us with the compound," he said.

Rizvi started a Phase II trial of Cometriq at Memorial Sloan-Kettering in July 2012. As of this month, the trial has enrolled 4 patients of a planned 25. He said Exelixis has agreed to provide undisclosed funding for the trial.

In data published in March in Cancer Discovery, Rizvi reported that 2 of the first 3 patients enrolled had confirmed partial responses to Cometriq, with a $66 \%$ decrease in measurable disease in one patient and a $32 \%$ decrease in the other. Both patients have remained progression free on treatment for 4-5 months.

The third patient has had stable disease for eight months on treatment. The fourth patient just started treatment and is too early to evaluate.

Alice Shaw, assistant professor of medicine at Harvard Medical School and a thoracic oncologist at Massachusetts General Hospital, said these results are comparable to other targeted lung cancer therapies and noted that Xalkori has a response rate of about $60 \%$ in $A L K$-positive lung cancer.

"We know cabozantinib
is a very good RET
inhibitor, so it was a
very logical step to
identify these patients,
test an available
inhibitor and see a
response." -Alice Shaw,
Harvard Medical School

"This is what we would have expected to see in an oncogene-addicted cancer-the preclinical data would predict that patients should be sensitive to a RET inhibitor. We know cabozantinib is a very good RET inhibitor, so it was a very logical step to identify these patients, test an available inhibitor and see a response," she said.

She compared the frequency of RET mutations to rearrangements of c-ros proto-oncogene 1 receptor tyrosine kinase (ROS1), a tyrosine kinase related to ALK, which are found in $1 \%-2 \%$ of NSCLC cases and predict response to ALK inhibitors including Xalkori. The fusion was first found in lung cancer in 2007, but its prevalence has become more widely appreciated in the last few years as more lung cancer samples have been genetically characterized.

Rizvi said the preliminary result was "sufficiently encouraging to expand the trial to be conducted as a multicenter study as part of the Lung Cancer Mutation Consortium.” The consortium is a National Cancer Institute initiative to prospectively examine NSCLC samples from patients and match them to appropriate therapies. It involves 16 cancer centers.

Rizvi said it was reassuring to see the clinical responses because other RET inhibitors were discontinued in lung cancer after poor clinical trial results. For example, Caprelsa missed its primary endpoint in two out of three Phase III lung cancer trials. The trials were completed before the fusion had been identified.

"These data speak to the importance of molecular characterization of 


\section{Box 1. Squamous smorgasbord.}

Although Ret proto-oncogene fusions offer the most promising example for how recent genomic analyses of lung cancer have identified newly actionable oncogenic alterations, additional clinical trials are seeking to validate other new targets, particularly in squamous cell lung cancers. Thus far, none of the ongoing trials have reported results as effective as Ret proto-oncogene inhibition.

One area of particular focus is mutations or amplifications of fibroblast growth factor receptors (FGFRs). In 2011, researchers published work suggesting that about $20 \%$ of squamous cell lung cancers (SCCs), a subtype of non-small cell lung cancer (NSCLC) associated with smoking, carry amplifications of FGFR1 (CD331). ${ }^{13}$ More recently, activating mutations in FGFR family members have been reported in lung cancer, and last week FGFR oncogenic fusions were reported in a variety of cancers including SCC. ${ }^{14,15}$

Peter Hammerman, instructor in medicine at Harvard Medical School and a thoracic oncologist at the DanaFarber Cancer Institute, is leading a trial of Iclusig ponatinib in patients with lung or head and neck cancer with FGFR alterations.

At the American Association for Cancer Research (AACR) meeting this week, Ariad Pharmaceuticals Inc. had a poster that showed Iclusig inhibits FGFR1-4 at low nanomolar concentrations and also potently inhibits the growth of cell lines bearing FGFR alterations, including FGFR1-amplified SCC.

"Ponatinib was selected because it is an FDA-approved agent, and the other high-potency FGFR inhibitors like
BGJ398 and AZD4547 are still in

Phase I," Hammerman said.

BGJ398 is a pan-FGFR inhibitor being developed by Novartis AG. The pharma presented data at the AACR meeting last year showing that one SCC patient with amplified FGFR1 had a partial response to the molecule.

AZD4547 is a pan-FGFR inhibitor being developed by AstraZeneca. This week at the AACR meeting, the company presented data showing that one SCC patient with FGFR1 amplification treated with the compound had a partial response that lasted 12 weeks. The patient was 1 of 21 with FGFR1 or FGFR2 (KGFR; CD332) alterations in various cancers that were treated with the compound, and the trial is ongoing.

Roman Thomas, chair of the Department of Translational Genomics at the University of Cologne, cautioned that FGFR amplifications in SCC may not be as straightforward to target as gene fusions. "We have data that shows that the biology of FGFR1 amplification is more complicated than originally thought, and we should also keep in mind that [ALK and RET] are more precise genomic alterations compared to amplifications. Unfortunately, though, we do not have response rate data from the AZD4547 or BGJ398 trials yet, so at this point we cannot really draw any conclusions yet."

Alice Shaw, assistant professor of medicine at Harvard Medical School and a thoracic oncologist at Massachusetts General Hospital, agreed that advances in SCC have not been translated as fast as she had hoped. "Squamous has been hard for a number of different reasons. In adenocarcinomas with ALK and ROS1 and RET, it seems like the pace has

been quicker."

In addition to FGFR-targeted therapies, patients with SCC who have activating mutations in discoidin domain receptor tyrosine kinase 2 (DDR2) have been enrolled in targeted clinical trials. Hammerman led a 2011 team that found DDR2 mutations drive $3 \%-4 \%$ of SCC cases and showed that Sprycel dasatinib can inhibit the kinase and block cell proliferation.

Bristol-Myers Squibb Co.'s Sprycel is a tyrosine kinase inhibitor marketed to treat acute lymphoblastic leukemia (ALL) and chronic myelogenous leukemia (CML).

Based on these results, a Dana-Farber investigator started a trial of Sprycel in patients with SCC who have DDR2 activating mutations. The study was terminated in January for undisclosed safety concerns.

Bruce Johnson, director of the Lowe Center for Thoracic Oncology at DanaFarber and leader of the aforementioned trial, declined to comment on its termination. Because of its relative lack of activity against DDR2, 3,16 Sprycel was being tested at $140 \mathrm{mg}$ daily orally, which is its highest approved dose.

Bristol-Myers is running its own trial of Sprycel at that dose in patients with lung cancer who have activating DDR2 mutations. That trial also is enrolling patients with inactivating mutations in BRAF. Last year, a retrospective analysis of patients with lung cancer who received Sprycel identified one patient with an inactivating mutation in BRAF who had a complete response to the compound. ${ }^{17}$

Bristol-Myers declined to comment.

$-C C$
James Vasselli, director of clinical research at AstraZeneca, said the company has conducted a retrospective analysis on lung tumor samples from previous vandetanib trials in NSCLC and has submitted an abstract to the American Society of Clinical Oncology. Results were not disclosed.

Gisela Schwab, EVP and CMO of Exelixis, said that based on Rizvi's early results, the company is designing its own trial of Cometriq in RET fusion-positive lung cancer.
"We're continuing the support of this study, but we are also evaluating and are interested in starting a company-initiated trial, and we are talking to various investigators, Dr. Rizvi included," she said. "The initial signal, even if only collected in a few patients, is strong, and that is one thing to consider when developing a drug-is the effect size going to be convincing enough to make a difference for that small of a patient population."

Rizvi said it will be important to run a multicenter trial to accrue enough patients to make a convincing case for the clinical benefit of RET inhibition. 
Table 1. Selected new targeted therapies in lung cancer. At least 12 clinical trials are testing or plan to test tyrosine kinase inhibitors with activity against recently identified oncogenic drivers of lung cancer in targeted patient populations, including Ret proto-oncogene (RET) fusions, amplifications or mutations in fibroblast growth factor receptors (FGFRs) and discoidin domain receptor tyrosine kinase 2 (DDR2) mutations. Source: ClinicalTrials.gov and University Hospital Medical Information Network.

\begin{tabular}{|c|c|c|c|c|c|}
\hline Compound & Indication & Status & Sponsor & Company collaborator & Clinical trial record \\
\hline \multicolumn{6}{|c|}{ RET fusions } \\
\hline Caprelsa vandetanib & $\begin{array}{l}\text { Non-small cell } \\
\text { lung cancer } \\
\text { (NSCLC) }\end{array}$ & Phase II & Seoul National University Hospital & $\begin{array}{l}\text { AstraZeneca plc (LSE:AZN; } \\
\text { NYSE:AZN) }\end{array}$ & NCT01823068 \\
\hline Caprelsa & NSCLC & Phase II & National Cancer Center Hospital East & AstraZeneca & UMIN000010095 \\
\hline Cometriq cabozantinib & NSCLC & Phase II & $\begin{array}{l}\text { Memorial Sloan-Kettering Cancer } \\
\text { Center }\end{array}$ & Exelixis Inc. (NASDAQ:EXEL) & NCT01639508 \\
\hline Iclusig ponatinib & NSCLC & Phase II & Massachusetts General Hospital & $\begin{array}{l}\text { Ariad Pharmaceuticals Inc. } \\
\text { (NASDAQ:ARIA) }\end{array}$ & NCT01813734 \\
\hline Nexavar sorafenib & NSCLC & Phase II & The Cancer Institute Hospital of JFCR & None & UMIN000007515 \\
\hline \multicolumn{6}{|c|}{ DDR2 or BRAF alterations } \\
\hline Sprycel dasatinib & $\begin{array}{l}\text { Squamous cell } \\
\text { lung cancer }\end{array}$ & Phase II $^{\mathrm{A}}$ & Dana-Farber Cancer Institute & None & NCT01491633 \\
\hline Sprycel & $\begin{array}{l}\text { NSCLC or other } \\
\text { cancers }\end{array}$ & Phase II & Bristol-Myers Squibb Co. (NYSE:BMY) & None & NCT01514864 \\
\hline \multicolumn{6}{|c|}{ FGFR amplifications or mutations } \\
\hline AZD $4547^{\mathrm{B}}$ & $\begin{array}{l}\text { Breast, squamous } \\
\text { lung and stomach } \\
\text { cancer }\end{array}$ & Phase II & The Royal Marsden & AstraZeneca & NCT01795768 \\
\hline AZD4547 plus docetaxel & $\begin{array}{l}\text { Squamous cell } \\
\text { lung cancer }\end{array}$ & Phase I/II & Eastern Cooperative Oncology Group & None & NCT01824901 \\
\hline AZD4547 & Solid tumors & Phase I & AstraZeneca & None & NCT00979134 \\
\hline Iclusig & $\begin{array}{l}\text { Lung and head } \\
\text { and neck cancer }\end{array}$ & Phase II & Dana-Farber & Ariad Pharmaceuticals & NCT01761747 \\
\hline BGJ398 ${ }^{\mathrm{B}}$ & Solid tumors & Phase I & Novartis AG (NYSE: NVS; SIX:NOVN) & None & NCT01004224 \\
\hline BGJ398 & Solid tumors & $\begin{array}{l}\text { Phase I } \\
\text { (Japan) }\end{array}$ & Novartis & None & NCT01697605 \\
\hline
\end{tabular}

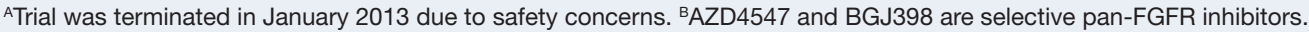

NSCLC and identification of appropriate subsets for targeted therapy," said Rizvi.

James Vasselli, director of clinical research at AstraZeneca, said the company has conducted a retrospective analysis on lung tumor samples from previous vandetanib trials in NSCLC and has submitted an abstract to the American Society of Clinical Oncology. Results were not disclosed.

Gisela Schwab, EVP and CMO of Exelixis, said that based on Rizvi's early results, the company is designing its own trial of Cometriq in RET fusion-positive lung cancer.

"We're continuing the support of this study, but we are also evaluating and are interested in starting a company-initiated trial, and we are talking to various investigators, Dr. Rizvi included," she said. "The initial signal, even if only collected in a few patients, is strong, and that is one thing to consider when developing a drug-is the effect size going to be convincing enough to make a difference for that small of a patient population."

Rizvi said it will be important to run a multicenter trial to accrue enough patients to make a convincing case for the clinical benefit of RET inhibition.

Schwab agreed. "Given the rarity of the fusion gene, in only $1 \%-2 \%$ of NSCLC patients, one has to screen quite a few patients," she said. "However, you can narrow down the number of patients a little bit by only screening those patients who aren't K-Ras or EGFR or ALK positive to enrich the population."

Indeed, Rizvi showed that 5 of 31 patients (16\%) screened were positive for RET fusions. He attributed the enriched percentage to the prerequisite that patients had never smoked and were negative for most other known drivers of lung cancer, including mutations in epidermal growth factor receptor (EGFR), K-Ras, neuroblastoma Ras viral (v-Ras) oncogene (NRAS), BRAF, HER2 (EGFR2; ErbB2; neu), phosphatidylinositol-4,5-bisphosphate 3-kinase catalytic subunit- $\alpha$ (PIK3CA), MAP kinase kinase 1 (MAP2K1; MEK1) and protein kinase $B$ (PKB; PKBA; AKT;AKT1), and fusions of ALK and ROS1.

One of the five $R E T$-positive patients had a previously unseen tripartite motif containing 33 (TRIM33)-RET fusion, whereas the other four had KIF5B-RET fusions. Foundation Medicine Inc. collaborated on screening patients for the mutations.

Schwab said even at a $1 \%-2 \%$ incidence, RET-positive NSCLC cases would still account for a large number of patients.

The American Cancer Society estimates that 228,190 cases of lung cancer will be diagnosed in 2013 , and about $80 \%-85 \%$ of lung cancers are NSCLC. At the low end, that would translate to about 1,800 RETpositive patients.

\section{RET party}

In addition to Exelixis, AstraZeneca and Ariad are now supporting investigator-initiated trials of their compounds in RET fusion-positive lung cancer.

AstraZeneca is working with two groups, one based at Seoul National University Hospital in South Korea, which plans to start a 
Phase II study this year, and one at the National Cancer Center Hospital East in Japan, which is enrolling patients.

"Based on the six-plus published papers on RET fusions in NSCLC, key opinion leaders in the field of NSCLC and we at AstraZeneca think that inhibition of RET in NSCLC patients carrying a RET fusion in their tumors has the potential for activity in this disease, so AstraZeneca is interested in evaluating vandetanib in RET fusion-positive NSCLC," said Vasselli.

Tim Clackson, CSO and president of R\&D at Ariad, said the biotech is supporting a multicenter, investigator-initiated trial of Iclusig in RET fusion-positive patients. The study will be run by Massachusetts General Hospital's Shaw.

Clackson noted that Iclusig has greater potency for RET than other marketed drugs and suggested that the structure of the drug could help combat the emergence of drug resistance.

"Our compound is two orders of magnitude more potent as a RET inhibitor than vandetanib or cabozantinib, at least in terms of $\mathrm{IC}_{50}$ in nonclinical studies," he said. "Also, by virtue of the design of the compound, we would expect Iclusig to overcome gatekeeper resistance mutations. It was designed to overcome all known resistance mutations in BCR-ABL because we built structural features into the drug that allow

\section{"These data speak to the importance of molecular characterization of NSCLC and identification of appropriate subsets for targeted therapy." -Naiyer Rizvi, Memorial Sloan-Kettering Cancer Center}

it to bypass gatekeeper mutations, and that ability translates to other kinases."

In research presented this week at the American Association for Cancer Research meeting in Washington, D.C., the company showed that Iclusig has an $\mathrm{IC}_{50}$ value of $0.16 \mathrm{~nm}$ for RET kinase and inhibits the growth of KIF5B-RET-transformed cells with an $\mathrm{IC}_{50}$ value of $11 \mathrm{~nm}$. In separate studies published by Exelixis and AstraZeneca, Cometriq had an $\mathrm{IC}_{50}$ value against RET of $5.2 \mathrm{~nm}$, whereas Caprelsa had an $\mathrm{IC}_{50}$ value of $100 \mathrm{~nm} .{ }^{11,12}$

Schwab said the overall target profile of Cometriq may contribute to its efficacy in patients with RET fusion.

Rizvi and Shaw noted that resistance always arises when targeted therapies are used, and they both plan to monitor the emergence of resistance in patients receiving RET inhibitors in their trials.

Rizvi said that despite the high activity of available drugs, there could be a place in the future for more selective RET inhibitors with fewer off-target effects. Caprelsa, Cometriq and Iclusig each carry black box warnings of toxicity on their labels.
"All three patients in our cabozantinib study have had dose reductions over time for toxicity, and there is significant interest in trying to identify and test more selective inhibitors," he said.

Cain, C. SciBX 6(14); doi:10.1038/scibx.2013.326

Published online April 11, 2013

REFERENCES

1. Drilon, A. et al. Cancer Discov.; published online March 27, 2013; doi:10.1158/2159-8290.CD-13-0035

Contact: Naiyer A. Rizvi, Memorial Sloan-Kettering Cancer Center, New York, N.Y.

e-mail: rizvin@mskcc.org

2. Cain, C. SciBX 4(2); doi:10.1038/scibx.2011.34

3. McCallister, E. BioCentury 19(39), A1-A4; Sept. 19, 2011

4. Kotz, J. SciBX 4(20); doi:10.1038/scibx.2011.559

5. Cain, C. SciBX 5(9); doi:10.1038/scibx.2012.219

6. Ju, Y.S. et al. Genome Res. 22, 436-445 (2012)

7. Kohno, T. et al. Nat. Med. 18, 375-377 (2012)

8. Lipson, D. et al. Nat. Med. 18, 382-384 (2012)

9. Takeuchi, K. et al. Nat. Med. 18, 378-381 (2012)

10. Soda, M. et al. Nature 448, 561-566 (2007)

11. Yakes, F.M. et al. Mol. Cancer Ther. 10, 2298-2308 (2011)

12. Carlomagno, F. et al. Cancer Res. 62, 7284-7290 (2002)

13. Weiss, J. et al. Sci. Transl. Med. 2, 62 ra93 (2010)

14. Cancer Genome Atlas Research Network. Nature 489, 519-525 (2012)

15. Wu, Y.-M. et al. Cancer Discov.; published online April 4, 2013; doi:10.1158/2159-8290.CD-13-0050

16. Hammerman, P.S. et al. Cancer Discov. 1, 78-89 (2011)

17. Sen, B. et al. Sci. Transl. Med. 4, 136ra70 (2012)

COMPANIES AND INSTITUTIONS MENTIONED

American Association for Cancer Research, Philadelphia, $\mathrm{Pa}$. American Cancer Society, Atlanta, Ga.

American Society of Clinical Oncology, Alexandria, Va. Ariad Pharmaceuticals Inc. (NASDAQ:ARIA), Cambridge, Mass. AstraZeneca plc (LSE:AZN; NYSE:AZN), London, U.K.

Bayer AG (Xetra:BAY), Leverkusen, Germany

Bristol-Myers Squibb Co. (NYSE:BMY), New York, N.Y.

Dana-Farber Cancer Institute, Boston, Mass.

Exelixis Inc. (NASDAQ:EXEL), South San Francisco, Calif.

Foundation Medicine Inc., Cambridge, Mass.

Harvard Medical School, Boston, Mass.

Massachusetts General Hospital, Boston, Mass.

Memorial Sloan-Kettering Cancer Center, New York, N.Y.

National Cancer Center Hospital East, Kashiwa, Japan

National Cancer Institute, Bethesda, Md.

Novartis AG (NYSE:NVS; SIX:NOVN), Basel, Switzerland Onyx Pharmaceuticals Inc. (NASDAQ:ONXX), South San Francisco, Calif.

Pfizer Inc. (NYSE:PFE), New York, N.Y.

Seoul National University Hospital, Seoul, South Korea University of Cologne, Cologne, Germany 